\title{
Evolutionary Game Analysis on the Supervision of Bad Loans in Commercial Banks
}

\author{
Jinliang Hua \\ Shanghai Academy, Shanghai University, shanghai, China \\ 774198276@qq.com
}

Keywords: Commercial bank; Non-performing loans; Eevolutionary game

\begin{abstract}
The economic man's rational behavior and information asymmetry and other reasons, often lead to the commercial bank has hidden the impulse of non-performing loans, resulting in inconsistent accounts of the situation, affecting the economic operation. In this game the situation of information asymmetry, evolutionary game based on the idea of the establishment of commercial banks and regulators in two groups of non dynamic replication system symmetry evolutionary game, evolutionary stable state analysis system under different circumstances. It is concluded that under the condition of different parameter values, the system will tend to be in a different state of equilibrium.
\end{abstract}

\section{Introduction and Literature Review}

Due to the constant changes of the macroeconomic situation at home and abroad, the domestic banking industry is facing the pressure of increasing the stage of non-performing loans because of the serious negative impact on the commercial banks of our country. In the context of deproductivity, destocking and deleveraging, individual companies are losing money, causing non-performing loans to banks and financial institutions to climb. The non-performing loan ratio will affect the ability of the bank to support the economy.

In order to further study the commercial bank non-performing loans, we can start with the causes of non-performing loans. Only a detailed understanding of its reasons, can the right remedy. Zhao Yi-jun (2016) analyzed the causes of non-performing loans from a macro point of view, and analyzed the factors of non-performing loan ratio [3]. By analyzing the present situation, Ji Min and Li Ang (2016) think that the factors of non-performing loans include: macroeconomic factors, banks' own factors, real estate industry factors [4]. Yi Li (2016) believes that people's weak credit consciousness and other reasons led to personal non-performing loans [5].

Through the exploration of the causes of non-performing loans, some scholars also put forward some suggestions for these problems.Guo Minle (2016) puts forward concrete measures to prevent non-performing loans according to the situation of non-performing loans in China's commercial banks from 2006 to 2015[6].Tian Linfeng (2016) analyzed the influencing factors of commercial banks' non-performing loan rate from the macro aspect, and provided some countermeasures and suggestions to prevent the emergence of non-performing loans [7].Although there are a large number of studies on non-performing loans of commercial banks in China, they are generally static. The problems existing in regulators and commercial banks and the stable state of both parties under different parameters cannot be analyzed from the point of view of dynamic supervision. Therefore, based on the perspective of evolutionary game, this paper establishes a dynamic model to study the regulatory bodies and commercial banks in depth, considering the equilibrium state of both parties under different parameters.

\section{Game theory Model Construction between Commercial Banks and Regulators}

First, commercial banks and regulators have the characteristics of long-term continuity, second, commercial banks and regulators in the game information is not completely symmetrical; third, Commercial banks and regulators are rational agents[8].

During each game, commercial Banks have a certain probability to choose to hide or not to hide, 
and regulators have a certain probability to choose inspection strategy or not to check strategy. Therefore, the model can be obtained from the perspective of social welfare, as shown in table 1:

Table 1 model table of commercial Banks and regulators

\begin{tabular}{|c|c|}
\hline Verification; Don't hide & $\begin{array}{l}\text { Regulatory revenue function } \Pi_{11}^{N}: \Pi_{11}^{N}=-\mathrm{c}+\mathrm{R} \\
\text { The return function of a commercial bank } \Pi_{11}^{M}: \Pi_{11}^{M}=W+F\end{array}$ \\
\hline Verification; The hidden & $\begin{array}{l}\text { The return function of bank regulators } \Pi_{12}^{N}: \Pi_{12}^{N}=R-\mathrm{c}+\mathrm{E} \\
\text { The return function of a commercial bank } \Pi_{12}^{M}: \Pi_{12}^{M}=W+I-E\end{array}$ \\
\hline No verification; Don't hide & $\begin{array}{l}\text { Regulatory revenue function } \Pi_{21}^{N}: \Pi_{21}^{N}=0 \\
\text { The return function of a commercial bank } \Pi_{21}^{M}: \Pi_{21}^{M}=W+F\end{array}$ \\
\hline No verification; The hidden & $\begin{array}{l}\text { Regulatory revenue function } \Pi_{22}^{N}: \Pi_{22}^{N}=-G \\
\text { The return function of a commercial bank } \Pi_{22}^{M}: \Pi_{22}^{M}=W+I\end{array}$ \\
\hline
\end{tabular}

$\mathrm{C}$ indicates the regulatory inspection cost paid by the regulator ; $\mathrm{R}$ indicates the profit from the regulatory choice of the inspection strategy; $\mathrm{G}$ indicates the loss caused by the regulator's choice not to verify; $\mathrm{W}$ indicates the normal income of the commercial bank; F said commercial banks do not conceal the long-term returns on non-performing loans; I mean the short-term benefits of commercial banks hiding non-performing loans; E indicates the amount of penalties imposed on commercial banks.

Through the analysis of the above four cases, all the possible returns of commercial Banks and regulators under different strategies are calculated. Then the payoff matrix of the game between commercial Banks and regulators is given (see table 2).

Table 2 revenue matrix of the game between commercial Banks and regulators

\begin{tabular}{c|c|c|c}
\hline \multirow{2}{*}{\begin{tabular}{l}
\multirow{2}{*}{$\begin{array}{l}\text { type } \\
\text { type }\end{array}$} \\
\cline { 2 - 3 } \multicolumn{3}{c}{ check: $\mathrm{p}$}
\end{tabular}} & Don't hide: $\mathrm{T}$ & The hidden: 1-q \\
\hline \multirow{3}{*}{ regulators } & Do not check: $1-\mathrm{p}$ & $\mathrm{R}-\mathrm{c} ; \mathrm{W}+\mathrm{F}$ & $\mathrm{E}-\mathrm{c}+\mathrm{R} ;-\mathrm{E}+\mathrm{W}+\mathrm{I}$ \\
\cline { 2 - 4 } & & $0 ; \mathrm{W}+\mathrm{F}$ & $-\mathrm{G} ; \mathrm{W}+\mathrm{I}$ \\
\hline
\end{tabular}

\section{The Game Model between Commercial Banks and Regulators is Solved and Analyzed}

In this section, we will analyze the strategic choice between commercial banks and regulators under the condition of limited rationality. The probability of choosing inspection strategy is $p$, the probability of choosing non-inspection strategy is 1-p, and the probability of commercial bank choosing not hiding is $\mathrm{Q}$, and the probability of hiding is 1-q[9].

According to the idea of biological evolution and replication dynamics, the replicon dynamic equations of regulators and the replicon dynamic equations of commercial Banks can be obtained respectively:

$$
\begin{aligned}
& F(p)=d p / d t=p(1-p)\left[q\left(\Pi_{11}^{N}-\Pi_{21}^{N}\right)+(1-q)\left(\Pi_{12}^{N}-\Pi_{22}^{N}\right)\right] \\
& F(q)=d q / d t=q(1-q)\left[p\left(\Pi_{11}^{M}-\Pi_{12}^{M}\right)+(1-p)\left(\Pi_{21}^{M}-\Pi_{22}^{M}\right)\right]
\end{aligned}
$$

$\mathrm{F}(\mathrm{p})$ represents the rate of change over time in the probability of regulators choosing the "check" strategy, and F(q) represents the rate of change over time in the probability of commercial Banks 
choosing "not to hide".

The equation (1) and equation (2) is equal to zero, respectively, can be regulatory system steady state point $\left(p_{1}=0, p_{2}=1, p^{*}=\frac{F-I}{-E}\right)$, and the commercial bank system steady state point $\left(q_{1}=0, q_{2}=1, q^{*}=\frac{E+R+G-c}{E+G}\right)$, which can supply chain financial and regulatory institutions combine to form a system, the system has 5 dynamic system balance, respectively is $(0,0),(0,1),(1$, $0),(1,1)$ and $\left(p^{*}, q^{*}\right)$. On this basis, the jacobian matrix is used to determine whether the five stable states of two differential equation systems equation(1)and equation (2) are evolutionary stability strategies.

The specific values of jacobian matrix in a stable state are shown in table 3:

Table 3 specific values of jacobian matrix

\begin{tabular}{ccccc}
\hline steady state & $\frac{\partial F(p)}{\partial p}$ & $\frac{\partial F(p)}{\partial q}$ & $\frac{\partial F(q)}{\partial p}$ & $\frac{\partial F(q)}{\partial q}$ \\
\hline$(0,0)$ & $E-c+G+R$ & 0 & 0 & $F-I$ \\
$(0,1)$ & $-c+R$ & 0 & 0 & $-F+I$ \\
$(1,0)$ & $c-R-E-G$ & 0 & 0 & $F-I+E$ \\
$(1,1)$ & $c-R$ & 0 & 0 & $I-E-F$ \\
$\left(\mathrm{p}^{*}, \mathrm{q}^{*}\right)$ & 0 & $\mathrm{p}^{*}$ & $\mathrm{q}^{*}$ & 0 \\
\hline
\end{tabular}

To $\Delta A=E-c+R+G, \Delta B=F-I \quad \Delta C=-c+R \quad \Delta D=F-I+E$, in which $\Delta A$ for hidden in the commercial bank, under the condition of regulatory inspection and verification, the social benefits balance between $\Delta B$ under the condition of the regulators do not check, commercial Banks are hiding and don't hide, the social benefits balance between $\Delta C$ said without hiding in the commercial bank, regulatory inspection and verification, the social benefits balance between $\Delta D$ said regulators in the case of inspection, commercial Banks social yield gap between hidden and not hide.

Case 1: $\Delta A>0, \Delta B>0, \Delta C>0, \Delta D>0$

At this time, the stability analysis of the four stable states of the system is shown in table 4 .

Table 4 stability analysis of system stability at $\Delta A>0, \Delta B>0, \Delta C>0, \Delta D>0$

\begin{tabular}{cccc}
\hline equilibrium point & Determinant symbol of $\mathbf{J}$ & Trace symbol of $\mathbf{J}$ & Result \\
\hline $\mathrm{p}=0, \mathrm{q}=0$ & + & + & Unstable point \\
$\mathrm{p}=0, \mathrm{q}=1$ & - & Uncertain & saddle point \\
$\mathrm{p}=1, \mathrm{q}=0$ & - & Uncertain & saddle point \\
$\mathrm{p}=1, \mathrm{q}=1$ & + & - & ESS \\
\hline
\end{tabular}

According to the analysis in table $4,(1,1)$ is the evolutionary stability strategy of the system, that is, regulators tend to check, commercial Banks tend not to hide. At this time, no matter what measures are taken by commercial Banks, the income of inspection is greater than that of non-inspection. Therefore, inspection is the best choice for regulators. For commercial Banks, no matter what measures the regulators choose, the non-concealed benefits are greater than the hidden ones. Therefore, it is the best choice for commercial Banks not to hide.

Case 2: $\Delta A>0, \Delta B<0, \Delta C<0, \Delta D>0$

At this time, the stability analysis of the four stable states of the system is shown in table 5 . 
Table 5 stability analysis of system stability at $\Delta A>0, \Delta B<0, \Delta C<0, \Delta D>0$

\begin{tabular}{ccll}
\hline equilibrium point & Determinant symbol of $\mathbf{J}$ & Trace symbol of $\mathbf{J}$ & Result \\
\hline $\mathrm{p}=0, \mathrm{q}=0$ & - & Uncertain & saddle point \\
$\mathrm{p}=0, \mathrm{q}=1$ & - & Uncertain & saddle point \\
$\mathrm{p}=1, \mathrm{q}=0$ & - & Uncertain & saddle point \\
$\mathrm{p}=1, \mathrm{q}=1$ & - & Uncertain & saddle point
\end{tabular}

From table 5 analysis, in this case there is no stable and unstable, this system is in a state of saddle points, suggesting that regulators and commercial Banks are unable to tend to a stable point, the whole system is in a state of cyclical swings.

Case 3: $\Delta A>0, \Delta B<0, \Delta C<0, \Delta D<0$

At this time, the stability analysis of the four stable states of the system is shown in table 6 .

Table 6 stability analysis of system stability at $\Delta A>0, \Delta B<0, \Delta C<0, \Delta D<0$

\begin{tabular}{cccc}
\hline equilibrium point & Determinant symbol of $\mathbf{J}$ & Trace symbol of $\mathbf{J}$ & Result \\
\hline $\mathrm{p}=0, \mathrm{q}=0$ & - & Uncertain & saddle point \\
$\mathrm{p}=0, \mathrm{q}=1$ & - & Uncertain & saddle point \\
$\mathrm{p}=1, \mathrm{q}=0$ & + & - & ESS \\
$\mathrm{p}=1, \mathrm{q}=1$ & + & + & Unstable point \\
\hline
\end{tabular}

According to the analysis in table $6,(1,0)$ is the evolutionary stability strategy of the system, that is, regulators tend to check, commercial Banks tend to hide. In this case, no matter what strategy the regulators choose, commercial Banks always choose the concealment strategy, because the benefits of choosing the concealment strategy are greater than those of non-concealment. For regulators, the inspection strategy must be chosen if they want to get the maximum benefit.

\section{Conclusion}

The equilibrium state of the regulators and commercial banks is decided by both sides of the game together. In the case of asymmetry, the two sides have their own choice strategies, and in the process of repeated game, the two sides continue to improve. According to the classification, we can get the following conclusion. (1) when the regulatory body does not inspect, the size of the short-term income and the long-term income of the commercial bank determines whether the commercial bank chooses the concealment strategy;(2)when the commercial banks are not hidden, the size of the revenue and the cost of supervision that the regulators check will determine whether the regulator chooses the inspection strategy [10].(3)When the commercial banks are hidden, the revenue from the inspection of the supervision institutions and the income of the loss at the time of the non - inspection determines whether the regulatory authority chooses to check the strategy .

\section{References}

[1] DEEPAK TOSH,SHAMIK SENGUPTA.Establishing evolutionary game models for CYBer security information exchange (CYBEX)[J].Journal of Computer and System Sciences, 2016(17):33-38

[2] ELA OZKAN - CANBOLAT,AYDIN BERAHAB.Application of Evolutionary Game Theory to Strategic Innovation[J].Procedia - Social and Behavioral Sciences,2016,235:685 - 693 
[3] Zhao Yijun.Macroeconomic factors influencing non-performing loans of commercial Banks [J]. Financial think tanks,2016,6:39

[4] Jimin, Leon. Causes of non-performing loans in China's commercial Banks [J]. Financial innovation, 2016, 16:83-84

[5] Yi Li. Causes and Countermeasures of personal Non-performing loans in Banking [J] .Economic Forum: 28: 95-96

[6] Guo folk music. Causes and preventive measures of non-performing loans in China's commercial Banks [J].Journal of xi 'an university of petroleum (social science)Learning edition), 2016,56:32-36

[7] Tian ling feng. Influence of macroeconomic factors on the non-performing loan ratio of commercial Banks and Suggestions on countermeasures[J],times finance,2016,10:103-104

[8] Wang tao. Evolutionary game analysis on the regulation of non-performing loans in commercial Banks [J]. Financial practice,2016,18: 42-43

[9] Zhi-yuan zhang. Study on financial supervision and game of financial risk in China in the post-financial crisis era [M]. Beijing: economic sciencePress, 2015

[10] Hanjingtao and Chenqun. Game stability analysis of the evolution of P2P lending platform operation and government supervision under uncertain conditions $[\mathrm{J}]$. shangIndustry research,2016,473:38-43 